\title{
HOW DO WE EVER GET UP? ON THE PROXIMATE CAUSATION OF ACTIONS AND EVENTS
}

\author{
Geert KEIL \\ Humboldt-Universität Berlin
}

\begin{abstract}
Summary
Many candidates have been tried out as proximate causes of actions: belief-desire pairs, volitions, motives, intentions, and other kinds of pro-attitudes. None of these mental states or events, however, seems to be able to do the trick, that is, to get things going. Each of them may occur without an appropriate action ensuing. After reviewing several attempts at closing the alleged "causal gap", it is argued that on a correct analysis, there is no missing link waiting to be discovered. On the counterfactual account of singular causation, the onset of belief or desire may perfectly well cause an action, although no kind of mental antecedent is ever a causally sufficient condition for a specific kind of action to occur.
\end{abstract}

One of my all-time favourite philosophical quotations is about getting out of bed. More precisely, it is about the agonies which precede getting up, agonies of which I have knowledge by acquaintance. William James once described what happens when we set about getting up "on a freezing morning in a room without a fire":

We think how late we shall be, how the duties of the day will suffer; we say 'I must get up, this is ignominious,' etc.; but still the warm couch feels too delicious, the cold outside too cruel, and resolution faints away and postpones itself again and again just as it seemed on the verge of bursting the resistance and passing over into the decisive act. Now how do we ever get up under such circumstances? If I may generalize from my own experience, we more often than not get up without any 
struggle or decision at all. We suddenly find that we have got up. A fortunate lapse of consciousness occurs; we forget both the warmth and the cold, we fall into some revery connected with the day's life, in the course of which the idea flashes across us, 'Hollo! I must lie here no longer' - an idea which at that lucky instant awakens no contradictory or paralyzing suggestions, and consequently produces immediately its appropriate motor effects. (James 1890, 524)

I have quoted this famous passage at length because it contains, if I may generalize from my own experience, a plausible phenomenological account of how actions of a certain kind begin. The passage indicates, as I shall argue, a solution to a familiar puzzle about the causation of action.

For the sake of argument, I shall assume that some version of the causal theory of action is correct. In fact, I do not think that actions can be defined as bodily movements caused in the right way by the onset of mental attitudes. Bodily movements occur, while actions are performed or executed. The familiar transitive/intransitive ambiguity of the verb "to move" ("John moved his body" vs. "John's body moved") reflects this difference, and it could well be the case that no analysis or definitional reduction of "transitive" movements to "intransitive" ones is possible that does not itself invoke the notion of doing, performing, executing or carrying out. Thus, as far as the causal theory's claim to have provided a definitional reduction of "doing something intentionally" is concerned, I am not going to accept the causal theory, not even for the sake of argument. For the present purpose, however, these reservations are irrelevant, for the question of what an action is can be distinguished from the question of what happens when someone acts, and my present concern is with the latter question only. What I do not reject is the following claim: Every time someone acts, a bodily movement occurs which is caused by some change in the agent's mental attitudes and which causes some further change in the world. It is one thing to hold that an act of raising my arm can be analysed as an event of my arm's rising plus $\mathrm{x}$, and it is quite another thing to hold that "every time I raise my arm, my arm rises" (Wittgenstein). Rejecting the first claim does not commit you to rejecting the second.

The causal theory of action holds that mental events can cause bodily movements, and that they do so via event causality, the only 
kind of causality there is. Within this frame, I would like to address the question of how the causal gap between the mental event and the occurrence of the bodily movement can be closed. I shall argue, first, that no kind of mental antecedent is ever a causally sufficient condition for a specific kind of bodily movement to occur. On the other hand, pro-attitudes, or belief/desire pairs, or intentions, or volitions sometimes are viewed as the causes of bodily movements, and correctly so. How can this be?

Speaking of gaps: Is it certainly not an exaggeration to say that a major part of the action theorist's business is to close gaps. I shall give a brief survey of these gaps first, in order to locate the one I am concerned with among the other gaps:

Mind the gap!

Gap between

gets bridged by

(1) desire and intention

practical reasoning

(2) intention and bodily movement

?? ?

(3) bodily movement and further effects

causation ("up to nature")

First, there is a gap between desire and intention to act. It is not desires as such (nor belief-desire pairs) that urge us to act, but desires that become intentions. Many of our desires never become intentions. For instance, desires that are directed towards ends beyond the agent's reach, or beyond his abilities, typically are not turned into intentions. Aristotle is certainly right in holding that things we know to be beyond our control, and not attainable by action, do not become objects of deliberation. ${ }^{1}$ The gap between desire and intention can be bridged by practical reasoning. Desires, one could say, serve as an input for practical reasoning, while intentions to act are the output.

There is a second gap, for not every intention results in an action. Not even every intention to act immediately does so. Future-direc-

1. "We deliberate about things that are in our control, and are attainable by action" (Aristotle, Eth. Nic., Bk. III, 1111 b). 
ted intentions involve problems of their own, but even "proximal intentions", as they are sometimes called, may never get realized for some reason or other, whether that be weakness of will, outer obstacles, neural malfunctioning, or the agent's changing his mind just at the moment the action was supposed to begin.

There is a third gap between the agent's bodily movement that constitutes his basic action and the further effect that he intends to bring about. ${ }^{2}$ If I am lucky, I will get water out of the pump by moving my arm in the appropriate way. Moving my arm, however, is not causally sufficient for the intended effect to take place. Davidson famously held that "we never do more than move our bodies: the rest is up to nature" (Davidson 1971, 59). If Mother Nature doesn't play her part, my action fails, which is not to say that I have done nothing. But I will not have brought about what I intended. One apt way of characterizing this gap is by distinguishing between what we do and what we bring about, as Melden and von Wright have done. ${ }^{3}$

Finally, there is a gap that does not occur in the table above, because its nature is quite different. There is a difference between the desired effect taking place and its being brought about intentionally, for its being brought about intentionally depends on its being brought about "in the right way". So-called deviant causal chains may occur, and gallons of ink have been spent in trying to spell out, in general terms and in a non-circular way, what the right way is. Wasted rather than spent, according to Davidson, and I have agreed with him elsewhere (cf. Keil 2000, 72-111). This last gap is conceptual in character, not causal. When it has opened up, nature has

2. For the present purpose, I am using the expressions "basic action" and "bodily movement" interchangeably. As has often been noted, the distinction between basic and non-basic actions does not point to two distinct kinds of action. Rather, what is basic about a "basic action" is its description. "If we speak, not of basic and non-basic actions, but of basic and non-basic descriptions of an action, the basic descriptions of an action may provisionally be defined as those from which all reference to its effects have been eliminated" (Donagan 1975, 337).

3. Von Wright couples this distinction with that between the result of an action and its consequence, the result being connected with the action "logically", while the consequence is a causal effect. "The thing done", he says, "is the result of an action, the thing brought about is the consequence of an action" (von Wright 1971, 67). 
played her part already, the agent too, and any bridging of the gap will have to consist in excluding such cases from the notion of bringing about something intentionally, and this can only be done by a better conceptual analysis, if at all.

My concern is with the second gap only, the gap between the mental antecedent which is considered to be the proximal cause of the bodily movement, and the beginning of the bodily movement. In action theory, many candidates have been tried out as proximate causes of actions: belief-desire pairs, volitions or acts of will, intentions, decisions, acts of self-determination, conclusions of practical reasoning, motives, acts of identifying with one's motive, or of throwing one's weight behind one's motive. Some of these propo- sals tend towards agent-causal accounts, some towards event-causal accounts.

I shall not be concerned with weighing up or choosing among these candidates today. Davidson once wanted to get by with beliefs and desires only; later he accepted intentions as well. Bratman, Harman, Searle, Brand, and Mele have argued in favour of intending as a distinctive attitude, not reducible to believing and desiring. Volitions had fallen into disrepute for some time, but they have been revived by the New Volitionalists (O'Shaughnessy, McCann, Goldman, Hornsby, and Lowe). Colin Mc Ginn $(1982,94)$ even has use for beliefs, desires, intentions and volitions.

The problem I shall discuss is one that all these candidates share. The problem is that none of them seems to be able to do the trick, that is, to get things going: All these mental states or events, so it seems, lack propelling force, for each of them may occur without an appropriate bodily movement ensuing. As I said above: The agent may change his mind at the last moment, he may be weak-willed or some external incident may interfere.

Sometimes, however, the action does take place, and we are inclined, in these cases, to cite one of the candidates mentioned above as the triggering cause of the action - under the assumption that some version of the causal theory of action is correct. I am using the label "causal theory of action" for event-causalist accounts only, as it is usual. Agent-causalist theories, however, do not evade the problem discussed here, for what we want to explain is why a certain action takes place at a certain moment, and citing "the agent" as the 
cause in a literal sense does not answer that question. Ontologically speaking, actions and events are occurrents, while agents are continuants, and as far as I see, Broad's objection to agent causation ${ }^{4}$ is still without a convincing reply. Most advocates of agent causality do not take seriously the challenge that lies in promoting continuants to causes (or causers) in a literal sense. Instead, persons are endowed with "causal powers", and the exercise of such powers is cited as the cause of further effects, which blurs the distinction between agent causality and event causality. Acts of exercise seem to be occurrents, and if such acts are needed to mediate between the agent and the events he is said to bring about, it is no longer literally true that the agent himself is the direct cause of these events, contrary to what the agent causalist claims. - Event causalists need not deny that agents are capable of bringing about something. What they deny is that "bringing about" is synonymous with "being the cause of", or that the latter notion is analytically contained in the former. Being the cause of, according to the event causalist, is a relation between events, while bringing about is a relation between agents and events.

Now often enough the alleged causal gap gets bridged, for actions do occur. Aristotle, in his scattered remarks on the practical syllogism, taught us that the connection between practical deliberation and action is an intimate one. Sometimes Aristotle even says that the conclusion of a practical syllogism is not a judgment, but the action itself. These remarks are in need of interpretation, however, and according to one possible interpretation is it only in cases where the action does occur that we can say, ex post, that the practical deliberation led to the action directly, without delay.

Kenny and Davidson stick to the claim that the conclusion of a practical deliberation is a judgment. According to Davidson, it is an "'all-out" positive evaluation of a way of acting", which he regards as equivalent with "an intention to act immediately" (Davidson $1985,214)$. Davidson is very close to Aristotle, however, in holding that the connection between such an "all things considered" judgment and action is extremely tight. He puts it this way: "If someone

4. "How could an event possibly be determined to happen at a certain date if its total cause contained no factor to which the notion of date has any application? And how can the notion of date have any application to anything that is not an event?" (Broad 1952, 215) 
forms an intention to act immediately, and nothing stops him, then he acts" (ibid.).

The salient point is, of course, the proviso "if nothing stops him". Though actions are caused by mental events, in Davidson's view, these mental events are not causally sufficient conditions, for such a connection would amount to a strict psycho-physical law between types of mental events and types of bodily movements, and, for all we know, there are no such strict laws. While it is controversial whether irrationality, such as weakness of will, really prevents someone from acting according to his intentions, or rather from forming all-things-considered judgments in the first place, hindrance and neural malfunctioning are clear cases. It would be crazy to deny that such obstacles, if they occur just at the right time, can preclude someone's intentions from becoming causally effective.

As a desperate move to close the causal gap, there remains the strategy adopted by Hobbes. Hobbes defines the will as "the last appetite [...] immediately adhering to the action" (Hobbes 1651, Pt. I, ch. 6, p. 48). Defining the will this way, Hobbes makes it true by definition that such an "appetite" is followed by an action. The proper mental antecedent is picked out by its temporal or even its causal position. Accordingly, Hobbes argues that if "we say in common discourse, a man had a will once to do a thing, that nevertheless he forebore to do", then obviously we are not dealing with "the last appetite in deliberating", but only with "an inclination" (ibid, 49).

Among the recent causal theorists of action, Myles Brand is alarmingly close to this Hobbesian move. Brand demands that there be

no causal space between the mental antecedent and the beginning of the physiological chain. That is, on an adequate Causal Theory, the mental antecedent must proximately cause the physiological chain leading to overt behavior (Brand 1984, 20).

Even if we agree, for the sake of argument, to the demand of "proximate" causation, we are left with the hard question which kind of mental antecedent fulfils this demand. How can the proximate cause be characterized in a non-question-begging way? If nothing but a bare postulate will do, the causal theory of action is in a deplorable position. 
We face the following dilemma: Either we describe the mental antecedent, in the familiar way, as an intention, a decision, a volition, a belief-desire pair, or something akin, picking it out by its intentional content. In this case, we are doing without a causally sufficient mental antecedent, since, for all we know, "[t]he presence of a given intentional state is always compatible with the absence of any set of explananda which it is invoked to explain" (Lennon 1990, 82). - Or we seize the second horn of the dilemma: We choose a characterization such as "the mental event that proximately causes the action", which gives little illumination, and will expose us to some version of the logical connection argument, for in this case the mental cause is picked out by reference to its effect. (There are several versions of the logical connection argument. The problem with an Hobbesian characterization of the mental antecedent is not that the effect is mentioned but that its occurrence is implied. $)^{5}$

To be sure, picking out an event by reference to its effect cannot deprive it of its causal efficacy. ${ }^{6}$ But what we were after was a causally sufficient mental antecedent of an action, that is, a condition or a set of conditions "which being realized, the consequent invariably follows", as Mill defined causes (Mill 1843, Bk. III, Ch. V, § 3, p. 322). Obviously, from the fact that the causal gap sometimes gets closed it cannot be inferred that types of mental antecedents are causally sufficient conditions. On the other hand, if some version of the causal theory of action is correct, it looks as if there must be some causally sufficient antecedent, for ex hypothesi, actions do not occur uncaused.

The dilemma looks like a serious challenge to any causal account of how actions arise from antecedent mental conditions. I purport to

5. "Instead of requiring that a cause be describable in a generalisable way that does not contain any kind of mention of its effect, we require only that a cause be describable in a generalisable way that does not imply that it causes its effect" (Pears 1975, 101). For example, "X's fear of stammering causes his stammering" is unobjectionable, for the description of the causing event "does not even contain the covert implication that it causes stammering" (ibid., 103).

6. Davidson had to remind the advocates of the logical connection argument of this fact: "The truth of a causal statement depends on what events are described; its status as analytic or synthetic depends on how the events are described" (Davidson 1963, 14). 
show that this impression is false, and that on a correct analysis, although the mental antecedents of actions do not constitute causally sufficient conditions, there is no "causal gap" to be closed.

My general idea is the following: Evading the dilemma and solving the puzzle about the proximate causation of action is not a matter of further elaboration in action theory, it is a matter of uncovering mistaken assumptions about the nature of causation. The solution is to be sought in the theory of causality in general, and not in the philosophy of action or in the debate about mental causation.

Let me explain. It is widely agreed that even our best candidates for mental causes of actions are susceptible to interference. Philosophers of action often think that this susceptibility to interference is due to some 'anomalism of the mental'. This assumption is mistaken. The normative character and the "holism of the mental", as described by Davidson, are additional obstacles to strict psycho-physical laws, but the underlying problem affects the causation of events in general. Michael Dummett once described what he called a "well-known crux" about causation as follows:

If causes precede their effects, it seems that there can never be any certainty that a cause will bring about its effect; since, during the interval, something might always intervene to hinder the operation of the cause. Moreover, the supposition that there is a lapse of time between the occurrence of the cause and its fruition in its effect appears irrational: for if the effect does not take place immediately, what makes it come about when, eventually, it does? (Dummett 1954, 320)

Dummett speaks of temporal gaps between causes and effects here. While it is far from obvious that every temporal gap corresponds to a causal gap, the remedy for both seems obvious enough: If we simply forbid a lapse of time between cause and effect, there is no "interval" during which "something might intervene to hinder the operation of the cause". Dummett is reluctant to make this move because it would make causes simultaneous with their effects. ${ }^{7}$ This qualm, however, rests on the assumption that events are temporally unextended. ${ }^{8}$ To my mind, "point events" are inadmissible as causal relata, for causes

7. "One event is causally connected with another if it is either its immediate cause or it is one of its remote causes. To be its immediate cause, it must be simultaneous with it" (Dummett 1954, 322). 
and effects are changes, and changes take time. Causation, on this picture, is a relation between two changes (cf. Ducasse 1957). But be that as it may: To make things worse, not even the requirement of temporal proximity will preclude the possibility of interference. It remains true that "something might always intervene to hinder the operation of the cause" even if there is no interval to be filled. For if something does intervene, the effect will fail to materialize, and what happens instead is the interfering event. Interferences that bide their time need no temporal no-man's land, they will simply take the place of the effect they prevent.

Sometimes however, the expected effect does materialize, and we are inclined to tell a causal story about the happenings then, even if the event-type that the causing event is a token of is not a causally sufficient condition for an effect of the type in question, due to the possibility of interference.

Now back to the case of action. Let us recall the phenomenological account given by William James. The question I would like to address is whether we can reconcile this account with a causal account of the happenings.

The most striking feature in James' story is the seeming absence of a triggering mental event that sets the agent's body in motion. The person clearly intends to get up, and even some "resolution" has taken place, as James puts it, but obviously these mental states or events do not suffice, for a while, to get things going. Some additional impulse seems to be lacking. According to James, however, the agent suddenly finds, without such an impulse having occurred, that he has got up. Not a triggering event, but the absence of ,inhibitory ideas" has done the trick. ${ }^{9}$ Now certainly the absence of something, not being an event, cannot cause anything in a literal sense. Unfortunately, even this is sometimes disputed, but I am quite determined here: Causes are events, and like Davidson and Larry Lom-

8. In Wolfgang Spohn, this assumption is brought into the open: "If time is continuous and if variables are associated with points and not with intervals of time, then, presumably, direct causes either do not exist or are simultaneous with their effects" (Spohn 1990, 126).

9. "It was our acute consciousness of both the warmth and the cold during the period of struggle, which paralyzed our activity then [...]. The moment these inhibitory ideas ceased, the original idea exerted its effects" (James 1890, 524-5). 
bard, I call only changes events. The absence of obstacles is not a cause, but can contribute to an explanation of why something occurred, for explanations may mention 'negative conditions' as well, while only changes can be causes. Ontologically speaking, absences are facts and not events.

I maintain that the search for a missing link that closes the alleged causal gap is misguided, and my suggestion is that the idea of causal sufficiency is the culprit. The search for a missing link will not come to an end as long as singular causes are regarded as sufficient conditions, or as parts of sufficient conditions, or as "sufficient in the circumstances", as some philosophers like to say. Conceiving causes in terms of sufficient conditions presupposes a generic account of causation, while applying the notion of sufficiency to individual events simply does not make sense. Recall Mill's definition of "cause", which I quoted above: "The cause, then, philosophically speaking, is the sum total of the conditions [...] which being realized, the consequent invariably follows". It has often been objected that all events we ordinarily call causes are only parts of such sets of sufficient conditions. But this criticism does not cut deep enough. The popular distinction between "total" causes and "partial" or "con- tributory" causes is beside the point, for the deep problem with Mill's definition is the assumption that, given a certain kind of event, or some combination of causal factors, "the consequent invariably follows". Talk of invariable succession presupposes a generic account of causation: Events of a certain kind will always occur if certain conditions are fulfilled, and an individual event plays its causal role in virtue of being of a certain kind. On the other hand, asking under which conditions this particular event is "invariably followed" by another event doesn't make sense. Davidson made this point long ago ${ }^{10}$, but talk of individual events as sufficient or necessary conditions (or as parts of such conditions) is still widespread. Even Mackie's celebrated INUS account is not free from this obscurity.

10. Cf. Davidson 1967. The same holds for talk of events as necessary conditions: "Obviously, given the usual definition of necessary conditions, namely through implication and denial, it is strictly a mistake in category to speak of events as necessary conditions. I do so in fact only in a semantical respect, viz. as instantiating a description" (Danto 1973, 94). 
Definitions of "cause" in terms of invariable succession rely on the principle of the nomological character of causality, as Davidson has called it. The principle says that "if $c$ and $e$ are related as cause and effect, there exist descriptions of $c$ and $e$ that instantiate a strict law" (Davidson 1993, 312-3; cf. 1963, 16). Unfortunately, the principle of the nomological character of causality is untenable, and untenable for empirical reasons. The requisite strict empirical laws of succession do not exist, not even in fundamental physics. All successions can be interfered with, and therefore the lawlike sentences about the succession of events do not tell the truth about what the objects in their domain do. They do not state the facts. Nancy Cartwright overstates the point when claiming that "the" laws of physics lie: It's not the laws of physics that lie, but some laws, i.e., those laws that admit of a causal interpretation. The fundamental laws of physics that science is so proud of are not laws about the succession of events, but laws about the coexistence of properties, and these have no causal interpretation. ${ }^{11}$ Empirical regularities, on the other hand, are defeasible, and this fact provides a sufficient reason to rid ourselves of the idea of causal sufficiency.

Now all these are bold assertions, and I cannot defend them against the stock objections from philosophy of science here. ${ }^{12}$ What I can do is try to explain why under different assumptions about the nature of causality the impression that some causal gap is waiting to be bridged does not arise.

The problem with belief-desire pairs, intentions, or volitions as causes of actions was that their presence is always compatible with the absence of an appropriate effect in behaviour. From a view of causes as sufficient conditions, this fact disqualifies them as causes of actions. From a singularist view, however, the only moral to draw is that a given mental event cannot have caused an action if no action has taken place, which should be uncontroversial. Sometimes however, rationalizing belief/desire-pairs are followed by appropriate

11. The distinction between laws of succession and laws of coexistence goes back to Mill (cf. Mill 1843, Bk. III, Ch. V, § 1). Mill makes it clear that "unless there had been laws of succession in our premises, there could have been no truths of succession in our conclusions" (ibid.).

12. I have defended the "no causal laws"-view in great detail elsewhere: Keil 2000, 151-260. 
actions, and in these cases there is a strong suggestion that they played a causal role. A pretheoretical way to express the intuition that suggests itself here is the counterfactual: "Had the agent not entertained these beliefs and desires, the action would not have occurred." According to David Lewis' counterfactual account of causation, this pretheoretical judgement is already the core of an adequate analysis. On the counterfactual analysis of event causation, the singular causal sentence ,c caused $e$ " is true if and only if,

$-c$ and $e$ are individual events that both occurred, and

- if $c$ had not occurred, $e$ would not have occurred either. ${ }^{13}$

One may feel inclined to add the third condition that $c$ must have preceded $e$, but according to Lewis, "backtracking" counterfactuals should not be affirmed anyway, so that this third condition is redundant.

Hence we are talking about counterfactuals such as "Had the agent not desired $p$ and believed $q$, the action would not have occurred". ${ }^{14}$ Note that no special reference to mental causation is made here. Of course, the antecedent of the conditional describes something mental, but this fact does not imply that there is a special kind of mental causation. Counterfactual dependence may cut across the mental/physical distinction, and there may be true 'mixed' counterfactuals. For example, the mental cause could be given a physical characterization, if we find one, or it may be traced back to a physical cause, analysable as a further counterfactual dependence.

13. "If $c$ and $e$ are two actual events such that $e$ would not have occurred without $c$, then $c$ is the cause of $e$ " (Lewis 1973, 167). I neglect Lewis ' distinction between causation and causal dependence, because I do not share the sole motivation for this distinction: his assumption that the causal relation is transitive. Cf. Keil 2000, 288-291 and 295-298.

14. Talk of believing and desiring simpliciter is a bit sloppy, given the assumption that beliefs and desires are states or dispositions. More precisely, "it is changes in the attitudes, which are events, which are the often unmentioned causes. [...] And we can often turn a causal explanation which mentions beliefs or desires into an explanation which refers to an event or events by saying the cause of the action was the advent of one or both of the belief-desire pair" (Davidson 1993, 288; cf. 1963, 12). 
For example this one: If the alarm clock had not rung, I would not have acquired the belief that it was time to get up. This is a counterfactual with a physical antecedent and a mental consequent. (As John Searle would put it: world-to-mind direction of fit in perception, mind-to-world direction of fit in action.)

Another remarkable trait of such a counterfactual analysis is its tense: The counterfactual dependence is always established ex post factum, in the face of two factual events. (A conditional can only be contrary-to-fact if there is a fact. Saying this, I commit myself to the metaphysical view that unlike the past, the future is not factual.) This ex post character not only of stating counterfactuals, but of the very existence of counterfactual dependence between individual events amounts to a reversal of the Humean perspective on causation, which is often overlooked. The question is no longer which features an event $c$ must possess so that we can infer that some event $e$ will occur. This was Hume's question, and given the synthetic character of causal truths, this question indeed provokes a sceptical answer. The new question is: given that $c$ and $e$ both occurred, what does it mean that $c$ was the cause of $e$ ? This question captures the point of a singular causal statement better, for in singular causal statements, the holding of a relation is asserted. The existence of the relata, on the other hand, is presupposed. When the holding of the relation is asserted, the existence of the relata is no longer an open question. ${ }^{15}$ This is true of relational statements in general: The judgment "Alan is Bill's brother" presupposes that two persons named Alan and Bill exist, while it asserts that they are related as brothers. The question of whether two events are causally related or not arises only if the relata exist. Seen this way, there is no good reason to burden the analysis of singular causal statements with the problem of induction.

Now let us consider once again William James' vivid account of how we sometimes manage to get up. Recall the central passage: "[H]ow do we ever get up under such circumstances? [...] We suddenly find that we have got up". The moment of decision, or the pulling of the 'mental trigger' that 'sparks off' the action, is not given in experience, according to James. In the same vein, Zeno Vendler

15. Here I am indebted to Pardey $(1998,85)$. 
says:

[T] he very exercise of my 'efficacy', the 'act of will' which actualizes this sequence of events, does not appear at all in my experience; it is not an additional event that could be perceived between my thoughts and deliberations about the deed to be done, and the awareness of the act's being performed (Vendler 1984, 120).

Now I promised to reconcile this phenomenological account with a causal account of the happenings. The question is whether the alleged mental event that tips the balance after the agent has finished his deliberation is just not given in experience, or not present to the mind, or whether there is no such event. Given James' story, it seems that there must be such a triggering event, for the "resolution" that James mentions was obviously causally inert; it "fainted away and postponed itself again and again". Before you could blink an eyelid, however, the heroic deed took place, so obviously some further impulse occurred that got things going.

I propose to contemplate the following question: When would this triggering event have to occur? Let us recall the conditions it would need to fulfil. On the one hand, it is supposed to mediate somehow between my thoughts and deliberations and the deed. Nothing that could count as a physiological or behavioral part of the action can be present already, for if the bodily effect has begun to materialize, a triggering cause is no longer needed. On the other hand, on the picture of causes as sufficient conditions, the triggering cause must coincide temporally with the beginning of the action, for wherever there is temporal gap, there is a chance for the world to interfere. And not only for the world: many libertarian philosophers, including me, claim that freedom of action implies ability to refrain from doing something, in the sense that there is no point in time before the actual beginning of the action at which it was not possible for the agent to change his mind.

If, however, the triggering "event" we are after is supposed to occupy the turning-point between the mental happenings and the action, the implication must be taken seriously that it is not a temporally extended event at all, but literally a point in time. This is the moral Vendler draws: "The moment of choice' [...] is [...] simply the moment of time at which deliberation leaves off, and action (if 
one decides upon) begins" (ibid.). ${ }^{16}$

This would explain, of course, why the alleged missing link is not given in experience: because it does not exist. For if it is temporally unextended, it is nothing that occurs. Nothing happens there. And where nothing happens, nothing can be caused. (Roman Ingarden does define events as unextended entities, and physicists call these entities "point events". But under the assumption that events and only events are the relata of the causal relation, we are well advised to side with Lombard and Davidson who call only changes events, and with Aristotle who claims that every change takes time. This is not only a terminological matter, for if events are supposed to be causal relata, the nature of these entities will have serious implications for the metaphysics of causation. Some authors do assume that causation is a relation between point events, or instantaneous states. If causes and effects are temporally unextended, however, most of the singular causal statements ever uttered would be false. It would not be true that lightnings cause fires, that cuts with a knife cause bleeding, etc. To my mind, this implication doesn't say much for the view in question. So, whatever the merits of point events, they do not seem to be suited as causal relata.)

To conclude. The attempts at closing the "causal gap" between mental antecedents and bodily actions are ill-conceived. On the counterfactual approach to causation, the singular causal sentences that the causal theory of action relies on need not be rejected. My wish to catch the early train, together with my belief that getting up now is the only way to achieve this aim, may perfectly well cause my getting up now. (Or, if you find the belief/desire version unsatisfactory, interpolate intentions: My intention to get up may cause my getting up.) Those who think otherwise erroneously reason from the fact that no type of mental antecedent guarantees that an appropriate

16. O'Shaughnessy puts it this way: "I suggest that the seeming automatism amounts to no more that this: that in the instant in which actual time and intended-act-time are seen to coincide, there is nothing left for one to do but act. Small wonder, for their time is one; and the great error is to postulate a necessary temporal gap, as if to allow space for some unmotivated mental mid-air leap. But it is a parody of this position to suppose that in that instant of realization one has lost power of choice, for that is precisely what one is exercising" (O'Shaughnessy 1973, 381-2). 
action will take place to the conclusion that some missing link is waiting to be discovered. On the counterfactual approach, however, looking for the cause of an action is looking for a preceding event that a given action was counterfactually dependent upon. True enough, I could have changed my mind, I could have been weak-willed or otherwise irrational and something could have interfered. In the present case, however, none of these things happened, and nothing prevented my attitudes from exerting their effects. This is exactly what James says: "The moment these inhibitory ideas ceased, the original idea exerted its effects".

The mere possibility of interference does not break chains of counterfactual dependence between individual events. If something interferes, on the other hand, no bodily action occurs, and the question of what caused it does not arise. Thus, part of the solution to the initial puzzle is the observation that while susceptibility of interference makes an analysis in terms of sufficient conditions impossible and is not compatible with the view that a singular causal statement entails a strict causal law, it does not make singular causal statements false. From the fact that, $c$ having happened, $e$ can still be prevented, we do not infer that $c$ was not the cause in case $e$ is not prevented.

If you think of causes as sufficient conditions, on the other hand, or as instantiating strict laws of succession, you will always be disturbed by the fact that no mental antecedent guarantees that the action occurs and you will look for an additional impulse to close the alleged causal gap. Without this impulse, so it seems, the action cannot start off. But on the view proposed, a mental antecedent which allows for interference may nevertheless be the cause of the bodily movement it rationalizes in a given case where nothing does interfere. In consideration of the factive character of singular causal statements, it is only natural that the counterfactual, causal dependence between the events in question can only be established in retrospect.

The point at which the action begins to materialize is literally a point in time, hence temporally unextended, and this explains why it is not given in experience, so that we can "suddenly find that we have got up", as James says. Practical deliberations and actions can touch one another in time, for while points in time cannot be tempo- 
ral neighbors, extended events can. Mental causes need not touch their effects temporally, however. Temporal contact has to be distinguished from causal contact. If there is a temporal gap, it becomes a causal gap only if what happens in between is a further change. If what goes on in between is a process of inertial motion, so to speak, the temporal gap is causally innocuous. ${ }^{17}$

Of course, judgements of counterfactual dependence between individual events have to be justified somehow, and their truth conditions have to be stated. Some philosophers, after all, deny that counterfactuals have determinate truth conditions at all. According to Quine, assessing their assertability will have to depend on "a sympathetic sense of the fabulist's likely purpose" (Quine 1960, 222). And according to those suffering from "epiphobia" (Fodor's phrase), counterfactuals with mental antecedents are even worse off. Kim says:

[W] hat the counterfactual theorists need to do is to give an account of just what makes those mind-body counterfactuals we want for mental causation true, and show that on that account those counterfactuals we don't want, for example, epiphenomenal counterfactuals, turn out to be false (Kim 1998, 71).

In absence of such an account, Kim says, "the counterfactual approach itself amounts to nothing more than a reaffirmation of faith in the reality of mental causation" (Kim 1996, 140).

I agree. My aim in this paper, far from arguing in detail for the counterfactual approach to event causation, was to show that if we adopt it, and reject the nomological account, good progress can be made in tackling a familiar puzzle about the causation of action. ${ }^{*}$

\section{REFERENCES}

17. "If [an event] is a remote cause of [another event], then it is so in virtue of being the immediate cause of the beginning of some process whose continuance is not regarded as requiring explanation, and whose arrival at a certain stage is in turn the immediate cause of the event in question" (Dummett 1954, 322). I admit that this suggestion needs further clarification when applied to the case of action, since there is no inertial motion, strictly speaking, outside mechanics.

* Thanks to the participants of the Bielefeld conference (in particular, to John Hyman) and to Neil Roughley for commenting on an earlier draft. Neil was also kind enough to check my English. 
Brand, Myles 1984: Intending and Acting. Toward a Naturalized Action Theory, Cambridge, Mass.

Broad, Charles D. 1952: Ethics and the History of Philosophy, London.

Danto, Arthur C. 1973: Analytical Philosophy of Action, Cambridge, Mass.

Davidson, Donald 1963: "Actions, Reasons, and Causes", in his EAE, 3-19.

- 1967: "Causal Relations", in his EAE, 149-162.

- 1971: "Agency”, in his EAE, 43-61.

- 1985: "Replies", in: B. Vermazen and M. B. Hintikka (eds.), Essays on Davidson - Actions and Events, Oxford.

- 1993: "Replies", in R. Stoecker (Ed.), Reflecting Davidson, Berlin / New York.

- EAE: Essays on Actions and Events, Oxford 1980.

Donagan, Alan 1975: "Von Wright on Causation, Intention, and Action", in: P. A. Schilpp and L. E. Hahn (Eds.), The Philosophy of Georg Henrik von Wright, La Salle, Ill. 1989, 333-351.

Ducasse, C. J. 1957: "On the Analysis of Causality", in his Truth, Knowledge and Causation, London/New York 1968, 15-20.

Dummett, Michael 1954: "Can an Effect Precede its Cause?", in his Truth and Other Enigmas, London 1978, 310-332.

Hobbes, Thomas 1651: Leviathan, ed. by W. Molesworth, London 1839.

James, William 1890: The Principles of Psychology, New York 1950, Vol. 2.

Keil, Geert 2000: Handeln und Verursachen, Frankfurt am Main.

Kim, Jaegwon 1996: Philosophy of Mind, Boulder, Col.

- 1998: Mind in a Physical World, Cambridge, Mass.

Lennon, Kathleen 1990: Explaining Human Action, London.

Lewis, David 1973: "Causation", in his Philosophical Papers, Vol. II, New York / Oxford 1986, 159-213.

McGinn, Colin 1982: The Character of Mind, New York.

Mill, John Stuart 1843: A System of Logic [= Collected Works VII/VIII], 
Toronto 1974.

O'Shaughnessy, Brian 1973: "Trying (as the Mental 'Pineal Gland')", Journal of Philosophy 71, 365-386.

Pardey, Ulrich 1998: "Zwei Arten von singulären Kausalurteilen”, in: Uwe Scheffler / Klaus Wuttich (Eds.), Terminigebrauch und Folge- beziehung, Berlin, 73-90.

Pears, David 1975: Questions in the Philosophy of Mind, London.

Quine, W.v.O. 1960: Word and Object, Cambridge, Mass.

Spohn, Wolfgang 1990: "Direct and Indirect Causes", Topoi 9, 125-145.

Vendler, Zeno 1984: The Matter of Minds, Oxford.

von Wright, Georg Henrik 1971: Explanation and Understanding, Ithaca, New York. 